\title{
GERM CELL TUMOURS OF THE OVARY IN CHILDREN AND ADOLESCENTS:
} A CLINICAL STUDY OF 109 PATIENTS IN A SPECIALIZED CANCER CENTRE

\author{
Irfan UI Islam Nasir, Muhammad I. Ashraf, Muhammad F. Shah, Awais A. Malik, \\ Muhammad T. Pirzada, Abdul W. Anwer, Aamir A. Syed, Abid Q. Qazi \\ Department of Surgical Oncology, Shaukat Khanum Memorial Cancer Hospital and Research Centre, Lahore, \\ Pakistan \\ Received: 26 January 2017 / Accepted: 25 December 2017
}

\begin{abstract}
Objective: Paediatric ovarian germ cell tumours (GCTs) are rare tumours with malignant tumours extremely rare.

Methods: All the paediatric patients who received treatment for histology proven ovarian GCT at Shaukat Khanum Memorial Cancer Hospital from January 2006 to December 2014 were retrospectively reviewed. Patients over the age of 18 years were excluded from the study. A total of 109 patients were included in the study. A set of parameters were identified to record initial clinical presentation and examination, imaging and laboratory investigations including tumour marker levels. Decisions of multidisciplinary team meetings, surgical treatment, neo-adjuvant, adjuvant chemotherapy and radiation data retrieved. Data analysis carried out using SPSS 20.
\end{abstract}

Results: In total 109 girls presented to our hospital during the study period, most of them above the age of 5 years, with dysgerminoma being the most common followed by yolk sac tumour. Most of the patients received treatment outside our hospital and were referred here for chemoradiotherapy. Fertility-preserving surgery was the most commonly performed surgical procedure with a mean follow-up of 50.4 months and $>75 \%$ overall 5 -year survival.

Conclusion: Regardless of histologic types, the outcomes of GCT can be improved with a multidisciplinary approach.

Key words: Dysgerminomas, germ cell tumours, ovarian tumours

\section{Introduction}

Germ cell tumours (GCTs) are rare tumours based on population analysis. In general, $80 \%$ of the GCTs are benign compared to $20 \%$ malignant GCT (constituting $2-3 \%$ of heterogeneous rare malignant paediatric tumours). ${ }^{[1]}$ GCTs have a bimodal age distribution with the first peak in infant age group and the second peak starts in adolescence. ${ }^{[2,3]}$ There is an increase in the incidence rate of GCTs in paediatric age group in Australia, Europe, and the United States. ${ }^{[4]}$ During the teen years, girls are slightly more frequently affected as compared to boys with a ratio of $1: 0.8 .^{[5]}$

\footnotetext{
Correspondence: Dr. Irfan Ul Islam Nasir,
}

Department of Surgical Oncology, Shaukat Khanum Memorial

Cancer Hospital and Research Centre, Lahore. Pakistan.

Email: irfanulislam@skm.org.pk
The ovarian GCT may present clinically with an ovarian mass. Signs and symptoms of precocious puberty or virilisation as a result of excessive hormone production may be present. ${ }^{[6]}$ Common sites of ovarian GCT are gonadal, presacral and retroperitoneal. Prognosis is mainly dependent on the site and age at diagnosis. ${ }^{[6]}$ The ovarian GCTs are mostly diagnosed in the fifth decade of life with $12 \%$ of patients below the age of 30 years, ${ }^{[7]}$ the most common are the juvenile granulosa cell tumours, which are mostly localized at presentation with an excellent prognosis, ${ }^{[8,9]}$ in contrast to that in adults, the adult-type granulosa cell tumours are often diagnosed at an advanced stage with an increased risk of endometrial cancer due to prolonged oestrogen exposure secondary to excessive tumour secretion. ${ }^{[10]}$

In the past, limited focus was given to chemotherapy for ovarian GCT, which has got a very clear role now. As there 
is gradual increase in the incidence of ovarian GCT, data from Pakistan regarding the profile of ovarian GCT at presentation and management are limited. We conducted this study to evaluate the role of chemotherapy in ovarian GCT as our current knowledge regarding incidence of ovarian GCT in Pakistan is incomplete. We have compiled data from our hospital which is a charity cancer hospital and referral centre. It is a retrospective study with design to gather demographic information, clinical presentation, management and survival outcome of ovarian GCT from a tertiary care cancer hospital in Pakistan.

\section{Methods}

Data of patients who received treatment for histology proven ovarian GCT at Shaukat Khanum Cancer Hospital from January 2006 to December 2014 were retrospectively reviewed. Patients over the age of 18 years and males were excluded from the study. Hospital records of all the patients with a diagnosis of ovarian GCT were included in the study. A set of parameters were identified to record initial clinical presentation and examination, imaging and laboratory investigations including tumour marker levels. Decisions of multidisciplinary team meetings, surgical treatment, neoadjuvant, post-operative chemotherapy and radiation data retrieved. Patients were stratified on the basis of age, clinical stage and type of tumour. Each individual ovarian GCT was categorized in terms of diagnosis, surgery, chemotherapy and outcome. Overall survival was calculated by subtracting date of last follow-up from date of the first presentation to hospital. Kaplan-Meier curves were used to determine estimated overall survival. All analyses were performed on SPSS version 20.

\section{Results}

A total of 109 girls presented to our hospital during the study period. Majority of the patients were from Punjab (70\%) followed by Khyber Pakhtunkhwa (25\%). Most of the patients $(72.4 \%)$ were above the age of 5 years. Gonads (78\%) are the most frequently involved site with dysgerminoma (41\%) being the most common tumour followed by yolk sac tumour (38.6\%) as shown in Table 1. Most of the surgeries were performed outside our hospital and were referred to our hospital for chemotherapy and completion surgery. However, the scope of this paper is to study the surgical treatment in our cohort and does not cover the details of chemotherapy regimens.
Table 1: Demographics

\begin{tabular}{l|c}
\hline Demographics & Patients $(\boldsymbol{n = 1 0 9 )}$ (\%) \\
\hline Area & $76(70.4)$ \\
\hline Punjab & $27(25.0)$ \\
\hline Khyber Pakhtunkhwa & $1(0.9)$ \\
\hline Afghanistan & $3(2.8)$ \\
\hline Islamabad & $2(2)$ \\
\hline FATA & \\
\hline Tumour location & $85(780)$ \\
\hline Gonadal & $24(22)$ \\
\hline Extragonadal & $5(4.6)$ \\
\hline Age & $25(23)$ \\
\hline$<1$ year & $79(72.4)$ \\
\hline 1-5 years & \\
\hline$>5$ years & $44(41.0)$ \\
\hline Histopathology & $42(38.6)$ \\
\hline Dysgerminoma & $20(18.1)$ \\
\hline Yolk sac tumour & $3(2.4)$ \\
\hline Teratoma &
\end{tabular}

Table 2: Management

\begin{tabular}{l|c}
\hline Primary surgery & Patients ( $\mathbf{n = 1 0 9 ) ( \% )}$ \\
\hline Fertility-preserving surgery & $74(68)$ \\
\hline Exploratory laparotomy & $13(12)$ \\
\hline TAH+BSO & $4(4)$ \\
\hline Cystectomy & $4(3)$ \\
\hline Biopsy & $3(3)$ \\
\hline No surgery & $11(10)$ \\
\hline Total & $109(100)$ \\
\hline Mets at presentation recurrence & \\
\hline Yes & $8(7.3)$ \\
\hline No & $101(92.7)$ \\
\hline Recurrence & \\
\hline Yes & $15(13.8)$ \\
\hline No & $94(86.2)$ \\
\hline Completion surgery & \\
\hline Debulking & $4(3.7)$ \\
\hline Laparotomy & $11(10.1)$ \\
\hline Irresectable & $2(1.8)$ \\
\hline
\end{tabular}

Seventy-four (68\%) patients underwent fertilitypreserving surgery, 13 (12\%) patients underwent exploratory laparotomy and no surgery was offered to $11(10 \%)$ patients as shown in Table 2 . Completion surgery 
was performed in $11(10.1 \%)$ patients and debulking was performed in $4(3.7 \%)$ patients while two were found irresectable.

Metastasis was present in $8(7.3 \%)$ patients and recurrence was found in $15(13.8 \%)$ patients on long-term follow-up as shown in Table 2. Patients had a mean follow-up of 50.4 months and $>75 \%$ overall 5 -year survival as shown in Graph 1.

\section{Discussion}

Ovarian GCTs account for 20-25\% of all ovarian neoplasms and only about $3 \%$ of these are malignant. GCTs are broadly classified as dysgerminomas and nondysgerminomas. This is important because their natural history and response to treatment, prognosis and survival times are very different. The main finding of our study was that the paediatric ovarian GCTs are although rare, and very few patients reach specialized centres; the incidence increases with increasing age.

In our study, dysgerminomas were the most common tumour followed by yolk sac tumour, whereas in a study conducted by Billmire et al. ${ }^{[11]}$ primarily carried out on children with ovarian GCT, teratoma was the most prevalent histology, while other studies also showed teratoma being the most common type of paediatric ovarian GCT. ${ }^{[12,13]}$ Most of the paediatric ovarian GCTs are gonadal (85) in our study as compare to extragonadal which was present in 24 patients which is similar to a study conducted by Marina et al., showing more gonadal involvement than extragonadal. ${ }^{[14]}$

The overall outcome for our patients was fairly good, as almost $75 \%$ of the patients were alive at 5 -year follow-up [Graph 1]. A report by the Children's Oncology Group from the USA showed that almost half of the patients diagnosed with Stage I malignant ovarian GCT had recurrent or persistent disease without the chemotherapy, but with chemotherapy, the overall survival was found to be around $95 \%$. $^{[15]}$

There are few limitations to our study. First, it was a retrospective study. Second, most of the patients were operated outside our hospital and were referred here for further treatment. Data on chemotherapy were difficult to

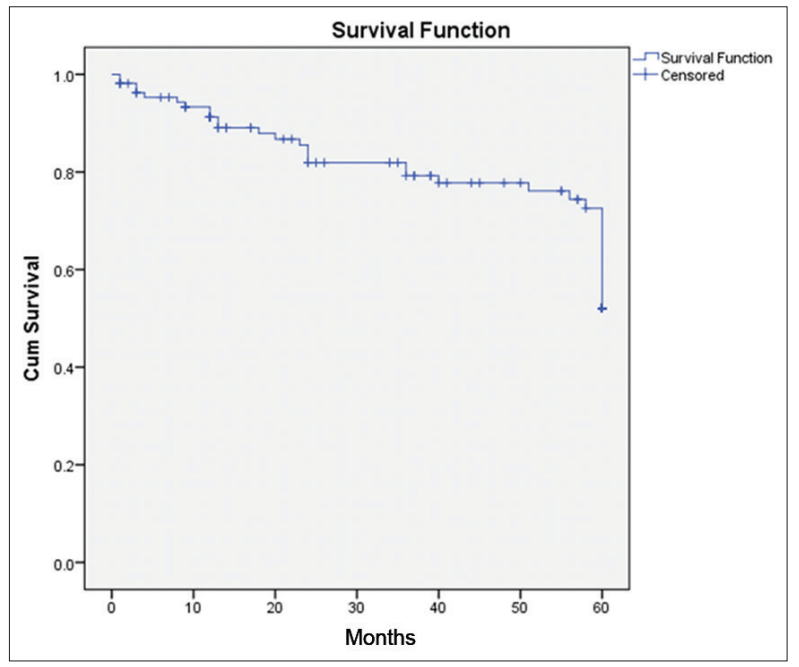

Graph 1: 5 Year Survival Plot

get with the lack of infrastructure. Third, chemotherapy regimen data are inadequate to comment on survival of this study population. Finally, there was little preoperative information available, including clinical and tumour marker levels posing diagnostic and management challenges in few cases. Here, we present gathered data from all patients who presented to our hospital during the study period and were analysed to give our local data. Further prospective studies with detailed information about pre-operative staging workup, chemotherapy regimen and post-surgical course should be undertaken.

\section{Conclusion}

Paediatric ovarian GCTs are curable tumours with good prognosis, survival can be improved by early diagnosis of proper treatment and follow-up. Awareness regarding general management principals of GCT in Pakistan needs to be much improved.

\section{Conflict of Interest}

The authors declare that they have no conflict of interest.

\section{References}

1. Poynter JN, Amatruda JF, Ross JA. Trends in incidence and survival of pediatric and adolescent patients with germ cell tumors in the United States, 1975 to 2006. Cancer 2010;116:4882-91.

2. Rescorla F. Paediatric germ cell tumours. Semin Surg Oncol 1999;16:144-58. 
3. Baade PD, Youlden DR, Valery PC, et al. Trends in incidence of childhood cancer in Australia, 1983-2006. Br J Cancer 2010;102:620-6.

4. Schneider DT, Calaminus G, Koch S, et al. Epidemiologic analysis of 1,442 children and adolescents registered in the German germ cell tumor protocols. Pediatr Blood Cancer 2004;42:169-75.

5. Kaatsch P. Epidemiology of childhood cancer. Cancer Treat Rev 2010;36:277-85.

6. Fresneau B, Orbach D, Faure-Conter C, et al. Sex-cord stromal tumors in children and teenagers: Results of the TGM-95 study. Pediatr Blood Cancer 2015;62:2114-9.

7. Quirk JT, Natarajan N. Ovarian cancer incidence in the United States, 1992-1999. Gynecol Oncol 2005;97:519-23.

8. Cecchetto G, Ferrari A, Bernini G, et al. Sex cord stromal tumors of the ovary in children: A clinicopathological report from the Italian TREP project. Pediatr Blood Cancer 2011;56:1062-7.

9. Schneider DT, Calaminus G, Wessalowski R, et al. Ovarian sex cord-stromal tumours in children and adolescents. J Clin Oncol 2003;21:2357-63.

10. Lee IH, Choi CH, Hong DG, et al. Clinicopathologic characteristics of granulosa cell tumors of the ovary: A multicenter retrospective study. J Gynecol Oncol 2011;22:188-95.

11. Billmire D, Vinocur C, Rescorla F, et al. Outcome and staging evaluation in malignant germ cell tumors of the ovary in children and adolescents: An intergroup study. J Pediatr Surg 2004;39:424-9.

12. Al Jama FE, Al Ghamdi AA, Gasim T, et al. Ovarian tumors in children and adolescents a clinical study of 52 patients in a university hospital. J Pediatr Adolesc Gynecol 2011;24:25-8.

13. Pauniaho SL, Salonen J, Helminen M, et al. Germ cell tumors in children and adolescents in Finland: Trends over 1969-2008. Cancer Causes Control 2014;25:1337-41.

14. Marina NM, Cushing B, Giller R, et al. Complete surgical excision is effective treatment for children with immature teratomas with or without malignant elements: A pediatric oncology group/Children's cancer group intergroup study. J Clin Oncol 1999;17:2137-43.

15. Billmire DF, Cullen JW, Rescorla FJ, et al. Surveillance after initial surgery for pediatric and adolescent girls with stage I ovarian germ cell tumors: Report from the children's oncology group. J Clin Oncol 2014;32:465-70. 